\title{
Emerging Value of Platelet-to-Hemoglobin Ratio and Monocyte-to-Hemoglobin Ratio in Assessment of Rheumatoid Arthritis Patients
}

\author{
NADA M. GAMAL, M.D.*; EMAN R. BADAWY, M.D.** and TAMER A. GHEITA, M.D.*** \\ The Departments of Rheumatology and Rehabilitation*, Clinical Pathology**, Faculty of Medicine, Assiut University and \\ Rheumatology \& Clinical Immunology Department***, Faculty of Medicine, Cairo University, Cairo, Egypt
}

\begin{abstract}
Background: Rheumatoid arthritis (RA) is chronic autoimmune disease associated with systemic inflammation that affects mainly synovial joints. Inflammation is the main reason of tissue destruction, physical disability and excess of mortality in RA. There is a need to find accurate inexpensive valuable inflammatory markers to be helpful in early diagnosis, prompt treatment and strict follow-up of RA patients.
\end{abstract}

Aim of Study: To assess platelet-to-hemoglobin ratio (PHR) and monocyte-to-hemoglobin ratio (MHR) in RA patients. In addition to evaluate their associations with clinical and laboratory markers of RA disease activity and severity.

Patients and Methods: The study included 175 adult RA patients and 186 age and gender healthy individuals were enrolled as control group. Disease activity score (DAS28) and RA medical records-based index of severity (RARBIS) were assessed in RA patients. PHR and MHR were measured in patients and controls.

Results: They were 154 females and 21 males RA patients with a mean age of $45.43 \pm 10.5$ years and disease duration of $9.3 \pm 0.47$ years. PHR and MHR were significantly higher in patients $(27.04 \pm 9.52,0.03 \pm 0.02)$ than controls $(21.58 \pm 5.6$, $0.02 \pm 0.01)$ respectively, $(p<0.001)$. PHR and MHR had diagnostic ability to discriminate RA patients from controls with sensitivity of $75 \%, 73.94 \%$ respectively and specificity of $53.23 \%$ in both. PHR had significant positive correlations with DAS28 ( $r=0.25, p=0.003)$, RARBIS $(r=0.20, p=0.041)$, erythrocyte sedimentation rate (ESR) $(r=0.41, p<0.001)$, Creactive protein (CRP) $(r=0.4, p<0.001)$ and anti-cyclic citrullinated peptide antibodies (anti-CCP abs) $(r=0.3, p=0.001)$. MHR was only correlated with CRP $(r=0.24, p=0.002)$. Multivariate linear regression for the increase in PHR among RA patients revealed that $\mathrm{ESR}(\beta=0.100 ; p<0.001, \mathrm{CI}=0.05-0.145)$ and CRP $(\beta=0.091 ; p=0.004, \mathrm{CI}=0.02-0.152)$ were significant predictors.

Conclusion: PHR and MHR were significantly increased in RA patients than controls. In addition, PHR and to lesser extent MHR were associated with RA disease activity and severity clinical as well as laboratory markers. This means

Correspondence to: Dr. Nada M. Gamal, The Department of Rheumatology and Rehabilitation, Faculty of Medicine, Assiut University they may serve as novel, inexpensive and easily obtainable inflammatory RA markers helping in evaluation and monitoring of RA patients disease activity and severity.

Key Words: Platelet-to-hemoglobin ratio-Monocyte-tohemoglobin ratio - Rheumatoid arthritis - DAS28 - RARBIS.

\section{Introduction}

RHEUMATOID arthritis (RA) is one of the most common autoimmune diseases characterized by chronic progressive inflammation of different organs, especially the synovia which infiltrated with neutrophils, macrophages, T cells, B cells and dendritic cells causing progressive destruction of cartilage and bone. This leads to joint damage, shortening life expectancy and decreasing quality of life [1]. Inflammation is the basic mechanism and primary cause resulting in disability and increased mortality in RA patients [2]. Therefore, assessment of inflammation in RA with reliable markers is necessary to better monitoring of the disease course, accurate management and therefore preferable long-term outcome.

The most commonly used markers for this aim in clinical practice are erythrocyte sedimentation rate (ESR) and C-reactive protein (CRP) [3]. However, both of them have some limitations, such as reflection of short term inflammatory activity, low recognition ability with other superimposed inflammatory conditions [4]

Systemic inflammation is associated with changes in circulatingblood either in blood cells counts or in composition allowing use of these changes for assessment the inflammatory activity [5]. Hemogram parameters particularly those including immune system elements are important in assessment of different diseases as they have a role 
in the inflammation control and also undergoing changes secondary to inflammation [6].

Platelets as one of the main blood cell components, having their main function in the maintenance of hemostasis; also play an important role in inflammation and immune responses, which may be attributed to their function in the hemostasis process [7]. Inflammation is considered to be a main platelets stimulant. Increased platelet counts may be detected during the clinical active RA stage while they are reduced in the remission periods induced by different treatment regimens [8]. Preliminary evidence on the platelets involvement in rheumatoid inflammation was provided by flow cytometric analyses that have detected a substantial number of platelet microparticles (MPs) in RA synovial fluid. These microparticles appear to have a major role in local release of cytokines such as interleukin 1 (IL-1), so joint inflammatory response development. In addition, MPs can interact with and activate fibroblast-like synoviocytes (FLS), which are important effector cells which mediate both immune activation and joint destruction [9]

Anemia is the most frequent extraarticular manifestation in RA, it can affect $60 \%$ of all RA patients at least once during their lifelong disease course [10]. Anemia not only contributes to fatigue and reduced quality of life in RA patients [11], but longstanding anemia can have harmful cardiovascular effects and contribute to increased mortality [12]. The relationship between RA inflammation and anemia was confirmed by significant associations between lower hemoglobin concentrations and higher disease activity score 28 (DAS 28) and by faster hemoglobin normalization after tumor necrosis factor a (TNF- $(\mathrm{x})$ blockade [13]

Different types of anemia have been seen in RA patients, including iron deficiency anemia (IDA), anemia of chronic disease (ACD), the combination of IDA and ACD (COMBI) anemia, megaloblastic anemia and hemolytic anemia [14]. ACDis the most common type in RA [15].

Monocytes, one of the innate immune cells, have a main role in the inflammation initiation and bone erosion in RA [16]. Infiltration of monocytes along with $\mathrm{T}$ and $\mathrm{B}$ cells into the joint and production of inflammatory mediators characterize the immunopathology of this disease. In addition, activation and migration of monocytes from peripheral blood into the joints are considered as early events in RA development [17] and circulating monocytes were already found to be increased in early RA patients [18]. The monocytic percentage in the immune response is essential and interferes with both the innate and adaptive arms of immunity [19]. Frequencies of all subsets of blood monocytes were found to alter in RA patients compared with healthy individuals [20].

Owing to changes caused by the inflammation in platelets, hemoglobin and monocytes in addition to influence of each them in RA pathogenesis; supposed that platelet-to-hemoglobin ratio (PHR) and monocyte-to-hemoglobin ratio (MHR) may act as novel potential inexpensive and easily obtainable inflammatory markers in assessing RA patients and their disease activity as well as severity. The aims of this study were to assess PHR and MHR in RA patients compared to healthy controls. In addition to evaluate their associations to clinical and laboratory markers of the disease activity and severity in RA patients.

\section{Patients and Methods}

\section{Study design and population:}

A comparative cross-sectional study included 175 adult RA patients diagnosed according to the 2010 American College of Rheumatology (ACR) and European League Against Rheumatism (EULAR) classification criteria [21], they were recruited from patients attending the Rheumatology and Rehabilitation Department, Faculty of Medicine, Assiut University in the period between September 2019 and March 2021. The control group included 186 age and gender matched healthy individuals recruited from the hospital staff and blood donors. Patients with hematologic diseases, diabetes mellitus, renal diseases, liver diseases, chronic obstructive pulmonary disease, malignancies, infections and other autoimmune diseases were excluded.

The study was approved by the ethics committee of the Faculty of Medicine, Assiut University, Egypt andwas conducted in accordance with the principles of the Declaration of Helsinki. An Informed consent was obtained from all participants prior to their sharing in the study.

\section{Data collection:}

All patients were subjected to detailed medical history and thorough clinical examination. The socio-demographic data, radiographic findings and therapeutic history of the study patients were recorded. Swollen joint count (SJC) and tender joint count (TJC) were estimated. The visual analogue scale (VAS) was reported by the patients and physician according to the patient global assessment (PGA) and physician global assessment (PhGA) of the disease activity respectively. RA activity was evaluated using disease activity score 28 (DAS28) [22] and categorized accordingly into 
(remission $<2.6$; low 2.6 to $\leq 3.2$; moderate $>3.2$ to $\leq 5.1$; and high $>5.1$ ). Disease severity was assessed by RA medical records-based index of severity (RARBIS) [23].

Laboratory investigations performed for RA patients included: Erythrocyte sedimentation rate (ESR), C-reactive protein (CRP), liver function tests [serum albumin, aspartate aminotransferase (AST), alanine aminotransferase (ALT)], kidney function tests [blood urea (BUN), serum creatinine], rheumatoid factor (RF) and anti-cyclic citrullinated peptide (anti-CCP) antibodies. Complete blood count with differential count was done for RA patients and controls as following: Two ml of venous blood were collected from each participant after complete aseptic conditions on EDTA tube then performed on automated blood cell counter (ADVIA 2021i, Seimens). PHR was calculated as the ratio of peripheral blood platelet count tohemoglobin level and MHR was calculated as the ratio of absolute count of peripheral blood monocyte to hemoglobin level.

\section{Statistical analysis:}

Data analysis was undertaken using SPSS version 20. Data were presented as frequencies and percentages or mean and standard deviation. After testing data normality, non-parametric tests were performed. Mann Whitney U test was used for comparison. Spearman's correlation was considered. Receiver operating characteristic (ROC) curve analysis was done to identify diagnostic ability of PHR and MHR to predict disease among patients and controls. Multivariate linear regression analysis was used to identify factors predicting increase in PHR among RA patients. The $p$-value $<0.05$ was considered significant.

\section{Results}

The study was carried out on 175 RA patients; 154 females $(88 \%)$ and 21 males $(12 \%)$ with a mean age $45.43 \pm 10.5(20-65)$ years and the mean of disease duration was $9.3 \pm 0.47(0.5-30)$ years. The 186 controls were age $(43.28 \pm 11.62 ; 18-60$ years) and gender (154 females and 32 males) matched $(p=0.163, p=0.069)$. The mean of body mass index (BMI) in RA patients was 30.72 $\pm 7.97 /$ 29.40 (15.00-61.20). 8 (4.6\%) of RA patients were current smokers, 87 (49.7\%) were passive smokers, $6(3.4 \%)$ were previous smokers while $74(42.3 \%)$ of them were non-smoker.

The clinical manifestations and medications of the patients are presented in Table (1), laboratory investigations of patients and controls showed in Table (2).
The means SJC and TJC were $4.20 \pm 0.45(0$ $24), 12.53 \pm 0.66(0-28)$ respectively. The PGA mean was 47.54 \pm 24.68 (5-100) and PhGA mean was $45.23 \pm 24.11$ (5-100). The mean of DAS28 was $5.27 \pm 1.74(1.50-8.56) .14$ patients were in remission; 15/46/100 had low/moderate/high disease activity respectively. The mean of RARBIS was $6.50 \pm 3.75(0-14)$.

In RA patients, the means of PHR (27.04 \pm 9.52$)$ and MHR $(0.03 \pm 0.02)$ were significantly higher than in healthy controls $(21.58 \pm 5.60,0.02 \pm 0.01)$ respectively; $(p<0.001)$ in both (Fig. 1A,B). The diagnostic ability of PHR and MHR for differentiation RA patients and controls is illustrated by ROC curve analysis (Fig. 2, Table 3).

Table (1): Clinical manifestations and medications of rheumatoid arthritis patients.

\begin{tabular}{|c|c|c|}
\hline & $\begin{array}{c}\text { Parameter } \\
\text { Number }(\%)\end{array}$ & $\begin{array}{l}\text { RA patients } \\
\quad(n=175)\end{array}$ \\
\hline General & $\begin{array}{l}\text { Morning stiffness } \\
\text { Fatigue } \\
\text { Weight loss }\end{array}$ & $\begin{array}{l}135(77.1) \\
135(77.1) \\
82(46.9)\end{array}$ \\
\hline Musculoskeletal & $\begin{array}{l}\text { Arthralgia } \\
\text { Arthritis } \\
\text { Deformity } \\
\text { Limitation of movements } \\
\text { Myalgia } \\
\text { Trigger finger } \\
\text { Subcutaneous nodules }\end{array}$ & $\begin{array}{l}166(94.9) \\
127(72.6) \\
64(36.6) \\
57(32.6) \\
108(61.7) \\
47(26.9) \\
44(25.1)\end{array}$ \\
\hline Eye & $\begin{array}{l}\text { Dryness } \\
\text { Blurring of vision } \\
\text { Burning eyes } \\
\text { Redness }\end{array}$ & $\begin{array}{l}71(40.6) \\
57(32.6) \\
10(5.7) \\
4(2.3)\end{array}$ \\
\hline Cardio-pulmonary & $\begin{array}{l}\text { Dyspnea } \\
\text { Cough }\end{array}$ & $\begin{array}{l}47(26.9) \\
9(5.1)\end{array}$ \\
\hline Renal & $\begin{array}{l}\text { Dysuria } \\
\text { Loin pain }\end{array}$ & $\begin{array}{l}55(31.4) \\
14(8.0)\end{array}$ \\
\hline GIT & $\begin{array}{l}\text { Diarrhea } \\
\text { Abdominal colic }\end{array}$ & $\begin{array}{l}7(4.0) \\
10(5.7)\end{array}$ \\
\hline CNS & $\begin{array}{l}\text { Sleep disturbance } \\
\text { Muscle weakness }\end{array}$ & $\begin{array}{l}109(62.3) \\
11(6.3)\end{array}$ \\
\hline Medications & $\begin{array}{l}\text { Methotrexate } \\
\text { Antimalarial drugs } \\
\text { Leflunomide } \\
\text { Salazopyrine } \\
\text { Cyclophosphamide } \\
\text { Azathioprine } \\
\text { Anti TNF- } \alpha \text { drugs } \\
\text { Steroids } \\
\text { NSAIDs }\end{array}$ & $\begin{array}{l}116(66.28) \\
168(96) \\
135(77.14) \\
39(22.28) \\
2(1.14) \\
2(1.14) \\
9(5.1) \\
113(64.6) \\
128(73.14)\end{array}$ \\
\hline
\end{tabular}

RA : Rheumatoid arthritis.

GIT : Gastrointestinal.

CNS: Central nervous system.

Anti-TNF- $\alpha$ drugs: Anti-tumor necrosis factor- $\alpha$ drugs.

NSAIDs: Non-steroidal anti-inflammatory drugs. 
Table (2): Laboratory investigations of rheumatoid arthritis patients and controls.

\begin{tabular}{|c|c|c|c|}
\hline $\begin{array}{l}\text { Variables } \\
\text { Mean } \pm \text { SD (range) }\end{array}$ & $\begin{array}{c}\mathrm{RA} \\
(\mathrm{n}=175)\end{array}$ & $\begin{array}{l}\text { Controls } \\
(\mathrm{n}=186)\end{array}$ & $\begin{array}{c}p- \\
\text { value }\end{array}$ \\
\hline WBCs $\left(10^{3} / \mathrm{ul}\right)$ & $6.48 \pm 2.66(2.10-26.77)$ & $6.84 \pm 2.30(3.70-15.05)$ & 0.080 \\
\hline Neutrophils $\left(10^{3} / \mathrm{ul}\right)$ & $3.50 \pm 2.38(0.60-25.08)$ & $3.81 \pm 1.87(1.32-13.04)$ & 0.012 \\
\hline Lymphocytes $\left(10^{3} / \mathrm{ul}\right)$ & $2.19 \pm 0.77(0.03-5.85)$ & $2.45 \pm 0.91(1.07-5.38)$ & 0.022 \\
\hline Monocytes $\left(10^{3} / \mathrm{ul}\right)$ & $0.44 \pm 0.02(0.01-3.340)$ & $0.33 \pm 0.01(0.10-0.92)$ & $<0.001$ \\
\hline Eosinophils $\left(10^{3} / \mathrm{ul}\right)$ & $0.20 \pm 0.01(0.00-2.57)$ & $0.20 \pm 0.01(0.05-0.50)$ & 0.106 \\
\hline Basophils $\left(10^{3} / \mathrm{ul}\right)$ & $0.05 \pm 0.01(0.00-0.57)$ & $0.03 \pm 0.01(0.00-0.18)$ & 0.229 \\
\hline Hemoglobin (g/dl) & $12.03 \pm 1.61(7.4-16.6)$ & $13.05 \pm 1.481(9.8-16.9)$ & $<0.001$ \\
\hline Platelets $\left(10^{3} / \mathrm{ul}\right)$ & $316.5 \pm 90.40(160-749)$ & $277.39 \pm 60.12(183-426)$ & $<0.001$ \\
\hline ESR (mm/1sthr) & $45.32 \pm 2.40(3.0-150.0)$ & - & \\
\hline CRP (mg/l) (+ve in 144) & $15.14 \pm 1.74(0.23-153.9)$ & - & \\
\hline $\operatorname{AST}(\mathrm{U} / \mathrm{L})$ & $22.75 \pm 1.25(2.00-197.00)$ & - & \\
\hline ALT (U/L) & $23.84 \pm 2.28(6.00-366.00)$ & - & \\
\hline Serum albumin $(g / L)$ & $41.11 \pm 4.09(28.00-50.0)$ & - & \\
\hline Blood urea (mmol/L) & $5.65 \pm 0.53(1.80-65.00)$ & - & \\
\hline Serum creatinine (umol/l) & $56.06 \pm 15.71(30.0-115.0)$ & - & \\
\hline $\mathrm{RF}(\mathrm{IU} / \mathrm{ml})(+\mathrm{ve}$ in 115$)$ & $129.16 \pm 13.89(3.31-872.0)$ & - & \\
\hline Anti CCP (U/ml) (+ve in 104) & $75.75 \pm 6.61(0.5-200.0)$ & - & \\
\hline
\end{tabular}

*Mann Whitney $\mathrm{U}$ test, Bold values are significant at $p<0.05$. AST : Aspartate aminotransferase.

WBCs : White blood cells. $\quad$ ALT : Alanine aminotransferase.

ESR : Erythrocyte sedimentation rate. RF : Rheumatoid factor.

CRP : C-reactive protein. Anti CCP abs: Anti-cyclic citrullinated peptide antibodies.

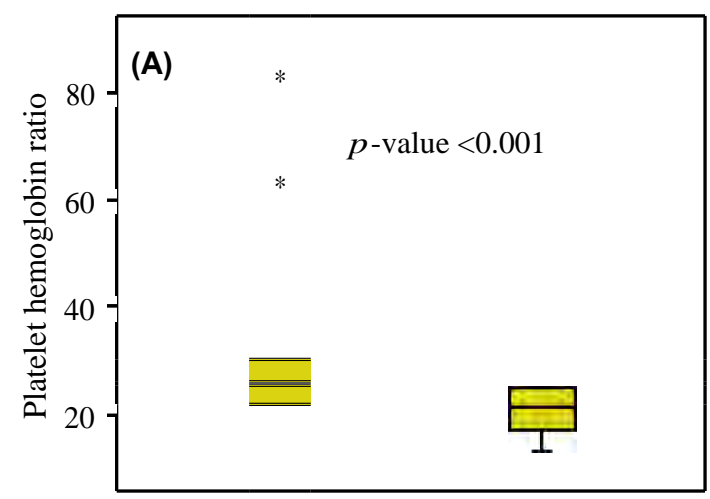

RA patients

Controls

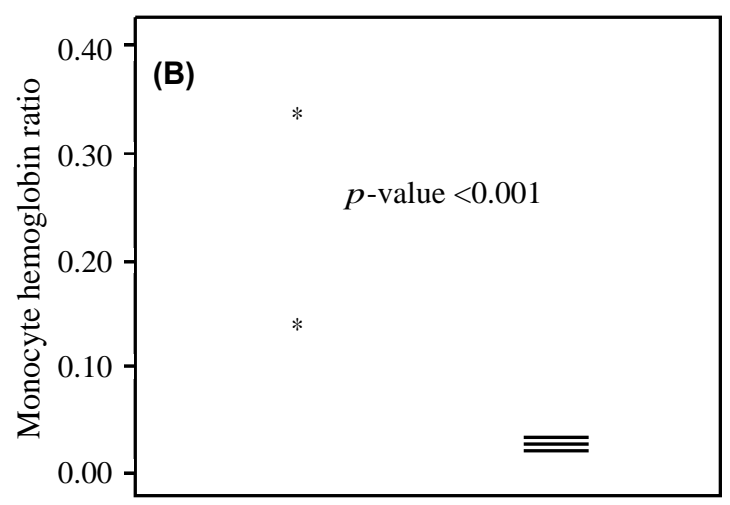

RA patients

Controls

Fig. (1): Box plots for platelet-to-hemoglobin ratio (A) and monocyte-to-hemoglobin ratio (B) in rheumatoid arthritis patients and controls.

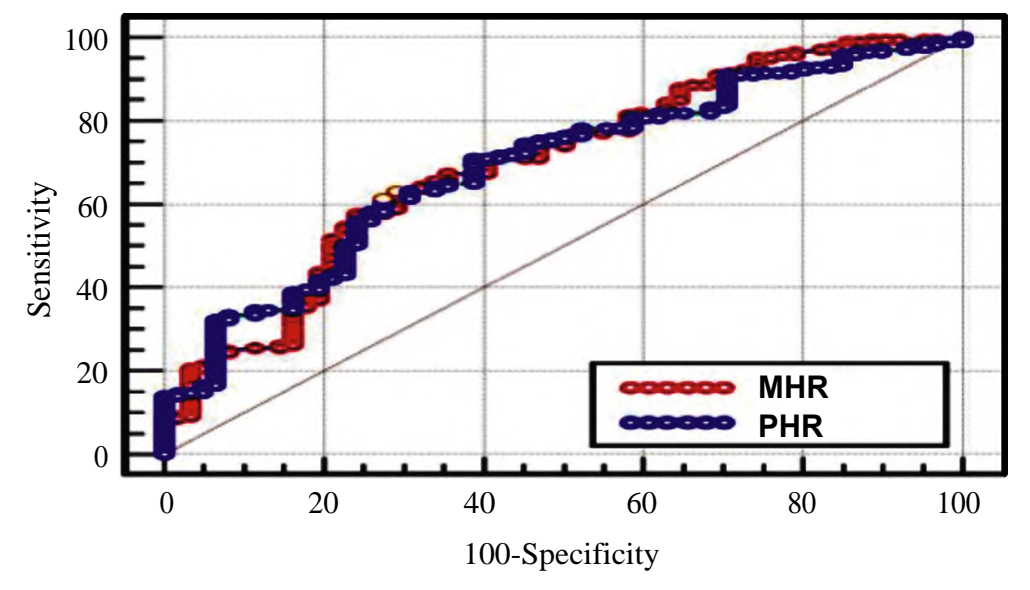

Fig. (2): Receiver operating characteristic (ROC) curve for prediction rheumatoid arthritis by platelet-to-hemoglobin ratio and monocyte-to-hemoglobin ratio. 
Table (3): Diagnostic ability of platelet-to-hemoglobin ratio (PHR) and monocyte-to-hemoglobin ratio (MHR) for differentiation between rheumatoid arthritis patients and controls.

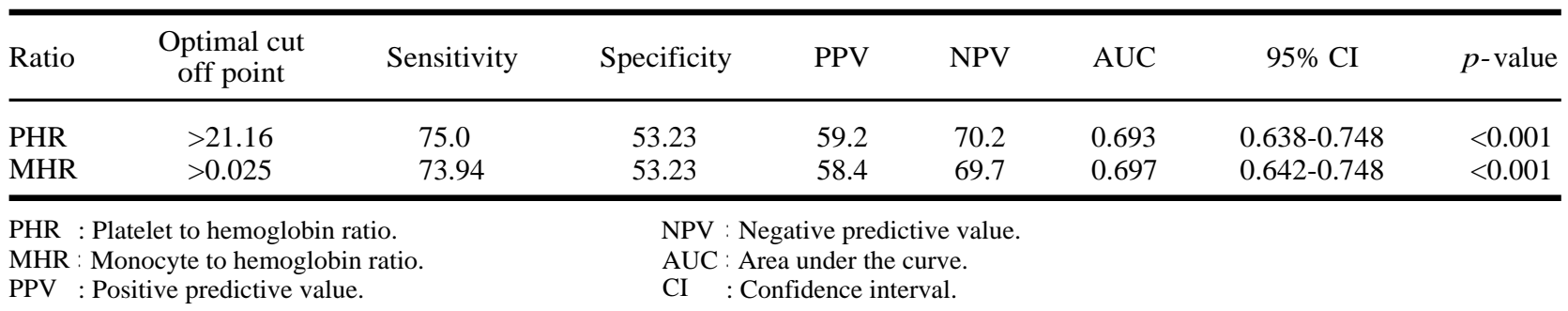

PHR had significant positive correlations with DAS28 ( $r=0.25, p=0.003)$, RARBIS ( $r=0.20$, $\mathrm{p}=0.041), \operatorname{ESR}(r=0.41, p<0.001), \mathrm{CRP}(r=0.40$, $p<0.001)$ and anti-CCP antibodies ( $r=0.30$, $p=0.001)$. MHR correlated significantly only with CRP ( $r=0.24, p=0.002)$. The increase of disease activity was associated with an increase in PHR but not in MHR (Table 4). Both PHR and MHR were significantly higher in RA patients with positive RF $(27.58 \pm 8.42,0.039 \pm 0.003)$ than those with negative RF $(25.98 \pm 11.37,0.034 \pm 0.002)$ respectively ( $p=0.043,0.044)$. In the same context, RA patients with positive anti-CCP antibodies had significant increase in both PHR and MHR $(28.12 \pm 8.28,0.039 \pm 0.003)$ compared to patients with negative anti-CCP antibodies $(25.52 \pm 10.91$, $0.034 \pm 0.002)$ respectively $(p=0.002,0.029)$.

Table (4): Association between platelet to hemoglobin ratio (PHR) and monocyte to hemoglobin ratio (MHR) with disease activity level in rheumatoid arthritis patients.

\begin{tabular}{lcc}
\hline Activity level & $\begin{array}{c}\text { PHR in } \\
\text { RA patients } \\
\text { Mean } \pm \text { SD }\end{array}$ & $\begin{array}{c}\text { MHR in } \\
\text { RA patients } \\
\text { Mean } \pm \text { SD }\end{array}$ \\
\hline DAS28: & & \\
Remission $(\mathrm{n}=14)$ & $23.86 \pm 5.59$ & $0.03 \pm 0.004$ \\
Low $(\mathrm{n}=15)$ & $24.04 \pm 9.21$ & $0.03 \pm 0.004$ \\
Moderate $(\mathrm{n}=46)$ & $26.75 \pm 7.15$ & $0.03 \pm 0.003$ \\
High $(\mathrm{n}=100)$ & $28.97 \pm 10.04$ & $0.03 \pm 0.003$ \\
$p$-value & $\mathbf{0 . 0 0 2}$ & 0.619 \\
\hline
\end{tabular}

*Kruskal Wallis Test, Bold values are significant at $p<0.05$.

RA : Rheumatoid arthritis.

PHR : Platelet to hemoglobin ratio.

MHR : Monocyte to hemoglobin ratio.

DAS28 : Disease activity score 28.

PHR had significant negative correlation with the age of RA patients ( $r=-0.20, p=0.027)$. MHR had positive significant correlation with disease duration $(r=0.20, p=0.20)$. No significant differences in PHR or MHR were detected between males and females RA patients $(p=0.610,0.304$ respectively).

Neither PHR nor MHR had significant correlation with BMI of RA patients. No significant dif- ferences were found in PHR or MHR within smoker versus non-smokers $(p=0.196, p=0.152) \mathrm{RA}$ patients.

Multivariate linear regression for the increase in PHR among RA patients revealed that ESR ( $\beta=0.100 ; p<0.001, \mathrm{CI}=0.05-0.145)$ and $\mathrm{CRP}$ $(\beta=0.091 ; p=0.004, \mathrm{CI}=0.02-0.152)$ were significant predictors.

\section{Discussion}

Rheumatoid arthritis (RA) is a chronic autoimmune disease, characterized by symmetric progressive polyarthritis leading to the irreversible destruction and deformities of joints. Inflammation is the key component of RA pathology $[24,25]$. The inflammatory process in RA involves inflammatory cells and molecules that cause changes in the number, shape and size of peripheral blood cells. Inflammatory cytokines such as IL-1, IL-6, and TNF- $\alpha$ in RA modulates erythropoiesis [26]

Rheumatoid arthritis assessment at the baseline and in the treatment follow-up is usually performed by DAS 28 system, which is calculated by the number of tender joints, number of swollen joints, patient assessment in VAS and ESR or CRP concentration. These measures may not have sufficient reliable results in some clinical cases [27,28]

Therefore, search for novel definitive easily applicable markers of RA inflammation is necessary to better clinical disease evaluation and monitoring its progression which will be helpful in strict management, efficient follow-up and subsequently improved outcome.

During the development and progression of the diseases, hematological changes are often occurred prior to morphological changes to reflect the clinical status. Hematological change is a kind of feedback to the systemic inflammation [29]

Platelets may play a great role in inflammation and immune-modulation postulated by the presence of crosstalk between markers of coagulation and the inflammatory system. Upon activation, platelets 
release pro-inflammatory platelets micro-particles, which interact with leucocytes resulting in joint and systemic inflammation in RA [30].

In this study, the mean of platelet count was significantly higher in RA patients compared to healthy controls. This was compatible with findings ofother studies [31,32]. The study of Khodashahi and colleagues [33] detected that platelet count was higher in the patients with active RA compared with those patients in remission, newly diagnosed RA patients and healthy controls.

Anemia is a very common manifestation of rheumatoid inflammation that could increase RA activity and decrease patient's quality of life [34] In RA, anemia may be caused by a shortened red blood cell lifespan, pathologic iron homeostasis induced by hepcidin and blunted response to erythropoietin. Cytokines also have a direct toxic effect on erythropoietin [13]

In this work, the mean of hemoglobin level in RA patients was significantly lower than in healthy controls. In agreement to this finding, hemoglobin levels were significantly decreased in patients with active disease and patients with inactive disease ( $p$-value $<0.001$ ) for each when compared to healthy controls [35]. In the same context, anemia was detected in high percent of RA patients; $84 \%$ in the study of Kumari and colleagues [36], $71 \%$ in Wolfe and Michaud study [10]. In contrast, no difference in hemoglobin was found between newly diagnosed RA, patients with active RA, patients in remission and controls in Khodashahi and coworkers study [33]

Infiltration of monocytes along with $\mathrm{T}$ and $\mathrm{B}$ cells into the joint and production of inflammatory mediators characterize the immunopathology of RA. The influence of the monocytic lineage in shaping the immune response is substantial and interferes with both the innate and adaptive arm of immunity. Thus, it is not surprising that controlling inflammation in disease-modifying antirheumatic drug (DMARD) non-responders may be achieved when targeting monocyte-derived cytokines, TNFa, IL-1, IL-6 or monocyte T cell interaction [37]. In this study, the mean of monocyte count was significantly increased in RA patients compared to healthy controls. This was consistent with study of Klimek and his colleagues [38]

Recently, there has been increasing interest to use hematologic biomarkers as sensitive measures of systemic inflammation. Increased neutrophilto-lymphocyte ratio (NLR) and platelet-tolymphocyte ratio (PLR) have been reported to be associated with cancer [39], diabetes [40] and psoriasis [41].

Recent studies have reported that NLR and PLR were significantly higher in patients with RA than in healthy controls $[\mathbf{2 4 , 2 5 , 4 2 , 4 3 ]}$. Moreover, they were positively correlated with the disease activity and inflammatory parameters, as well as predicted treatment responses in patients with RA $[24,25,44]$. An association was also found betweenlymphocyte-to-monocyte ratio (LMR) and disease activity in RA patients [45]. Egyptian studies threw light on the role of NLR in RA [28] and juvenile idiopathic arthritis [46]. In recent studies, NLR and PLR have been considered as promising markers in the assessment of disease activity on Egyptian RA patients $[35,47]$.

Presence of increased platelet and monocyte counts with decreased hemoglobin level in RA patients had proposed to use PHR and MHR as novel readily available objective markers for the assessment of RA disease activity and severity in this study. To best of our knowledge, only one studyevaluated PHR and MHR in RA patients [48]

This study showed that both PHR and MHR were significantly higher in RA patients compared to healthy controls. Moreover, results of this work showed that PHR and MHR had diagnostic ability to discriminate RA from healthy individuals. This was compatible with Liu and his colleagues study; the only available study mentioned these ratios as inflammatory markers in RA [48]. ROC in that study showed that AUC of PHR was $(0.884,95 \%$ CI $0.838-0.930)$ and of MHR was $(0.817,95 \%$ CI 0.760-0.874).

As it is known, ESR and CRP C-reactive were commonly used to indicate inflammation in RA. But these indicators have their limitations, ESR react slowly for inflammatory condition and CRP is lack of specificity to RA [49]. This study showed that PHR positively correlated with ESR, CRP and DAS28. Moreover, the factors predicting increase PHR level among RA patients were ESR and CRP. All these findings indicated that PHR was influenced from RA disease activity, it may suggested PHR can serve as a factor which detect active RA patients helping them to be treated promptly. In this work, MHR only had positive correlation with CRP; that made its role as a marker of RA inflammation is questionable and require more studies to prove it.

In this work, the increase of RA disease activity was associated with an increase in PHR. In addition to significant positive correlations of PHR with 
anti-CCP antibodies and RARBIS. Both PHR and MHR were significantly higher in RA patients with positive RF and anti-CCP antibodies compared to those had negative results. These findings indicated the presence of associations between PHR and to lesser extent MHR in RA patients and poor prognostic factors (higher disease activity, positive RF and anti-CCP antibodies) according to the EULAR recommendations [27]

Hemoglobin and platelet counts are wellestablished predictors of coronary artery disease outcomes, yet PHR was the strongest. The increased PHR was found to be an independent predictor for adverse outcomes in patients who underwent percutaneous coronary intervention [50]. This finding made suppose a relation between PHR and classic cardiovascular risk factors within RA patients as smoking and obesity. In this study, no significant associations were found between PHR and BMI of the patients. Also non-significant difference of PHR was detected in smokers and non-smokers within the study patients.

\section{Conclusion:}

In conclusion, PHR and MHR were significantly increased in RA patients than controls which means they may serve as biomarkers for RA diagnosis. In addition, PHR and to lesser extent MHR were associated with clinical and laboratory markers of RA disease activity as well as severity. This is very important in clinical practice; hematological markers as PHR and MHR are quite cheap and widely available and may be assessed in every patient. They may act as novel, inexpensive and easily obtainable inflammatory RA markers helping in evaluation and monitoring of RA patients disease activity and severity. A larger longitudinal study is recommended to confirm the present results and further demonstrate the relation to the disease outcome.

Declaration of conflicting interests: The authors declared no conflicts of interest with respect to the authorship and/or publication of this article.

Funding: This research did not receive any specific grant from funding agencies in the public, commercial, or not-for-profit sectors.

\section{References}

1- KUGYELKA R., KOHL Z., OLASZ K., MIKECZ K., RAUCH T.A., GLANT T.T., et al.: Enigma of IL-17 and Th17 cells in rheumatoid arthritis and in autoimmune animal models of arthritis. Mediators Inflamm, ID 6145810, 2016.

2- ZOCHLING J. and BRAUN J.: Mortality in rheumatoid arthritis and ankylosing spondylitis. Clin. Exp. Rheumatol., 27 (4): 127-130, 2009.
3- HOBBS K.F. and COHEN M.D.: Rheumatoid arthritis disease measurement: A new old idea. Rheumatology, 51 (6): 21-27, 2012.

4- COLGLAZIER C.L. and SUTEJ P.G.: Laboratory testing in the rheumatic diseases: A practical review. South Med. J., 98 (2): 185-191, 2005.

5- KISACIK B., TUFAN A., KALYONCU U., KARADAG O., AKDOGAN A., OZTURK M.A., et al.: Mean platelet volume (MPV) as an inflammatory marker in ankylosing spondylitis and rheumatoid arthritis. Joint Bone Spine, 75 (3): 291-294, 2008.

6- SCAPINI P. and CASSATELLA M.A.: Social networking of human neutrophils within the immune system. Blood, 124 (5): 710-719, 2014.

7- SEMPLE J.W., ITALIANO J.E. and FREEDMAN J.: Platelets and the immune continuum. Nat. Rev. Immunol., 11 (4): 264-274, 2011.

8- MILOVANOVIC M., NILSSON E. and JÄREMO P. Relationships between platelets and inflammatory markers in rheumatoid arthritis. Clin. Chim. Acta., 343 (12): $237-240,2004$

9- BOILARD E., NIGROVIC P.A., LARABEE K., WATTS G.F., COBLYN J.S., WEINBLATT M.E., et al.: Platelets amplify inflammation in arthritis via collagen-dependent microparticle production. Science, 327: 580-583, 2010.

10- WOLFE F. and MICHAUD K.: Anemia and renal function in patients with rheumatoid arthritis. J. Rheumatol., 33: 1516-1522, 2006.

11- PEETERS H.R., JONGEN-LAVRENCIC M., BAKKER C.H., VREUGDENHIL G., BREEDVELD F.C. and SWAAK A.J.: Recombinant human erythropoietin improves health-related quality of life in patients with rheumatoid arthritis and anaemia of chronic disease; utility measures correlate strongly with disease activity measures. Rheumatol. Int., 18: 201-206, 1999.

12- NISSENSON A.R., GOODNOUGH L.T. and DUBOIS R.W.: Anemia: Not just an innocent bystander? Arch. Intern. Med., 163: 1400-1404, 2003.

13- GANNA S.: The relationship between hemoglobin level and disease activity in patients with rheumatoid arthritis. Rev. Bras Reumatol., 54 (6): 437-440, 2014.

14-KULLICH W., NIKSIC F., BURMUCIC K., PÖLLMANN G. and KLEIN G.: Effects of the chemokine MIP-1 alpha on anemia and inflammation in rheumatoid arthritis. Z Rheumatol., 61: 568-576, 2002.

15- WILSON A., YU H.T., GOODNOUGH L.T. and NISSENSON A.R.: Prevalence and outcomes of anemia in rheumatoid arthritis: A systematic review of the literature. Am. J. Med., 116: 50-57, 2004.

16- DAVIGNON J.L., HAYDER M., BARON M., BOYER J.F., CONSTANTIN A., APPARAILLY F., et al.: Targeting monocytes/macrophages in the treatment of rheumatoid arthritis. Rheumatology (Oxford), 52: 590-598, 2013.

17- LIOTÉ F., BOVAL-BOIZARD B., WEILL D., KUNTZ D. and WAUTIER J.L.: Blood monocyte activation in rheumatoid arthritis: Increased monocyte adhesiveness, integrin expression, and cytokine release. Clin. Exp. Immunol., 106: 13-19, 1996. 
18- COULTHARD L.R., GEILER J., MATHEWS R.J., CHURCH L.D., DICKIE L.J., et al.: Differential effects of infliximab on absolute circulating blood leucocyte counts of innate immune cells in early and late rheumatoid arthritis patients. J. Clin. Exp. Immunol., 170: 36-46, 2012.

19- TACKE F. and RANDOLPH G.J.: Migratory fate and differentiation of blood monocyte subsets. Immunobiology, 211: 609-618, 2006.

20- YOON B.R., YOO S.J., CHOI Y., CHUNG Y.H., KIM J., YOO I. S., et al.: Functional phenotype of synovial monocytesmodulating inflammatory T-cell responses in rheumatoid arthritis (RA). PLoS One, 9: e109775, 2014.

21- ALETAHA D., NEOGI T., SILMAN A.J., FUNOVITS J., FELSON D.T. and BINGHAM C.O.: Rheumatoid arthritis classification criteria: An American College of Rheumatology/European League against Rheumatism collaborative initiative. Ann. Rheum. Dis., 69: 1580-1588.

22- PREVOO M.L., van' t HOF M.A., KUPER H.H., van LEEUWEN M.A., van de PUTTE L.B., van RIEL P.L.: Modified disease activity scores that include twentyeight-joint counts. Development and validation in a prospective longitudinal study of patients with rheumatoid arthritis. Arthritis Rheum., 38: 44-48, 1995.

23- CABRAL D., KATZ J.N., WEINBLATT M.E., TING G., AVORN J. and SOLOMON D.H.: Development and assessment of indicators of rheumatoid arthritis severity: Results of a Delphi panel. Arthritis Rheum., 53: 61-66, 2005.

24- USLU A.U., KÜÇÜK A., SAHIN A., UGAN Y., YILMAZ R., GÜNGÖR T., et al.: Two new inflammatory markers associated with Disease Activity Score-28 in patients with rheumatoid arthritis: Neutrophil-lymphocyte ratio and platelet-lymphocyte ratio. Int. J. Rheum. Dis., 18: 731$735,2015$.

25- CHANDRASHEKARA S., MUKHTAR A.M., RENUKA P., ANUPAMA K.R. and RENUKA K.: Characterization of neutrophil-to-lymphocyte ratio as a measure of inflammation in rheumatoid arthritis. Int. J. Rheum. Dis., 20: 1457-1467, 2017.

26- CHOY E.H. and PANAYI G.S.: Cytokine pathways and joint inflammation in rheumatoid arthritis. N. Engl. J. Med., 344: 907-916, 2001.

27- SMOLEN J.S., LANDEWÉ R., BIJLSMA J., BURMESTER G., CHATZIDIONYSIOU K., DOUGADOS M., et al.: EULAR recommendations for the management of rheumatoid arthritis with synthetic and biological diseasemodifying antirheumatic drugs: 2016 update. Ann. Rheum. Dis., 76: 960-977, 2017.

28- FAWZY R.M., SAID E.A. and MANSOUR A.I.: Association of neutrophil to lymphocyte ratio with disease activity indices and musculoskeletal ultrasound findings in recent onset rheumatoid arthritis patients. Egypt Rheumatol., 39: 203-206, 2017.

29- ZHANG Y., YIN Y., KUAI S., SHAN Z., PEI H. and WANG J.: Combination of neutrophil to lymphocyte ratio and platelet to lymphocyte ratio as diagnostic biomarker for rheumatoid arthritis. Int. J. Clin. Exp. Med., 9 (11): 22076-22081, 2016.

30- HARIFI G. and SIBILIA J.: Pathogenic role of platelets in rheumatoid arthritis and systemic autoimmune diseases:
Perspectives and therapeutic aspects. Saudi Med J., 37 (4): 354-360, 2016.

31- YAZICI S., YAZICI M., ERER B., ERER B., CALIK Y., OZHAN H. and ATAOGLU S.: The platelet indices in patients with rheumatoid arthritis: Mean platelet volume reflects disease activity. Platelets, 21 (2): 122-125, 2010.

32- TALUKDAR M., BARUI G., ADHIKARI A., KARMAKAR R., GHOSH U.C. and DAS T.K.: A study on association between common haematological parameters and disease activity in rheumatoid arthritis. J. Clin. Diagn. Res., 11 (1): EC01-EC04, 2017.

33- KHODASHAHI M., SAADATI N., REZAIEYAZDI Z., SAHEBARI M. and SAREMI Z.: Evaluation of Mean Platelet Volume in Rheumatoid Arthritis patients and its association with severity of the disease. Rheumatology Research Journal, 4 (3): 121-126, 2019.

34- BLOXHAM E., VAGADIA V., SCOTT K., FRANCIS G., SARAVANAN V., HEYCOCK C., et al.: Anaemia in rheumatoid arthritis: Can we afford to ignore it? Postgrad Med. J., 1031: 569-600, 2011.

35- HELAL R.M., EL-NAGGAR M.H., ZAHRA M.K. and ABO EL-NASR N.M.: Neutrophil to Lymphocyte Ratio and Platelet to Lymphocyte Ratio as Marker of Disease Activity in Rheumatoid Arthritis. Med. J. Cairo Univ., 87 (1): 139-145, 2019.

36- KUMARI M., MARWAH S. and ARYA V.: Study of anemia in rheumatoid arthritis. Int. J. Develop. Res., 8: 20568-20572, 2018.

37- SMILJANOVIC B., RADZIKOWSKA A., KUCAWARNAWIN E., KUROWSKA W., GRÜN J.R., STUHLMÜLLER B., et al.: Monocyte alterations in rheumatoid arthritis are dominated by preterm release from bone marrow and prominent triggering in the joint. Ann. Rheum. Dis., 77: 300-308, 2018.

38- KLIMEK E., MIKOLAJCZYK T., SULICKA J., KWASNY-KROCHIN B., KORKOSZ M., OSMENDA G., et al.: Blood monocyte subsets and selected cardiovascular risk markers in rheumatoid arthritis of short duration in relation to disease activity. Biomed Res Int., Article ID736853, 2014.

39- ZHANG Y., LU J.J., DU Y.P., FENG C.X., WANG L.Q. and CHEN M.B.: Prognostic value of neutrophil-tolymphocyte ratio and platelet-to-lymphocyte ratio in gastric cancer. Medicine, 97: e0144, 2018.

40- LI X., SHEN J., LU Z., CHEN M., FANG X. and WANG G.: High neutrophil-to-lymphocyte ratio is associated with increased carotid artery intima-media thickness in type 2 diabetes. J. Diabetes Investig., 8: 101-107, 2017.

41- PALIOGIANNIS P., SATTA R., DELIGIA G., FARINA G., BASSU S. and MANGONI A.A.: Associations between the neutrophil-to-lymphocyte and the platelet-tolymphocyte ratios and the presence and severity of psoriasis: A systematic review and meta-analysis. Clin. Exp. Med., 19: 37-45, 2019.

42- YANG Z., ZHANG Z., LIN F., REN Y., LIU D., ZHONG, et al. Comparisons of neutrophil-, monocyte-, eosinophil, and basophil-lymphocyte ratios among various systemic autoimmune rheumatic diseases. APMIS, 125: 863-871, 2017. 
43- ERRE G.L., PALIOGIANNIS P., CASTAGNA F., MANGONI A.A., CARRU C., PASSIU G., et al.: Meta-analysis of neutrophil-to-lymphocyte and platelet-to-lymphocyte ratio in rheumatoid arthritis. Eur. J. Clin. Investig., 49: e13037, 2019.

44- LEE H.N., KIM Y.K., KIM G.T., AHN E., SO M.W., SOHN D.H., et al.: Neutrophil-to-lymphocyte and plateletto-lymphocyte ratio as predictors of 12 -week treatment response and drug persistence of anti-tumor necrosis factor-a agents in patients with rheumatoid arthritis: A retrospective chart review analysis. Rheumatol. Int., 39: 859-868, 2019.

45- DU J., CHEN S., SHI J., ZHU X., YING H., ZHANG Y., et al.: The association between the lymphocyte-monocyte ratio and disease activity in rheumatoid arthritis. Clin. Rheumatol., 36: 2689-2695, 2017.

46- GHEITH R.E., EL GAZZAR I.I., BAHGAT D.M.R. and NOUR EL-DIN A.M.: Elevated tissue transglutaminase antibodies in juvenile idiopathic arthritis children: Relation to neutrophil-to-lymphocyte ratio and disease activity. Egypt Rheumatol., 39 (4): 233-237, 2017.
47- ABD-ELAZEEM M.I. and MOHAMED R.A.: Neutrophillymphocyte and platelet-lymphocyte ratios in rheumatoid arthritis patients: Relation to disease activity. Egypt Rheumatol., 40: 227-231, 2018.

48- LIU M., HUANG Y., HUANG Z., HUANG Q. and LI T.: A New Inflammatory Marker Associated With Disease Activity In Patients With Rheumatoid Arthritis: Platelet To Albumin Ratio. AB0204. Ann. Rheum. Dis-eular, 79 (1), 2020.

49- FENG J.F., HUANG Y. and CHEN Q.X.: The combination of platelet count and neutrophil lymphocyte ratio is a predictive factor in patients with esophageal squamous cell carcinoma. Transl. Oncol., 7: 632-637, 2014.

50- ZHENG Y.Y., WU T.T., CHEN Y., HOU X.G., YANG Y., ZHANG J.Y., et al.: Platelet-to-hemoglobin ratio as a novel predictor of long-term adverse outcomes in patients after percutaneous coronary intervention: A retrospective cohort study. Eur. J. Prev. Cardiol., 27 (19): 2216-2219, 2020.

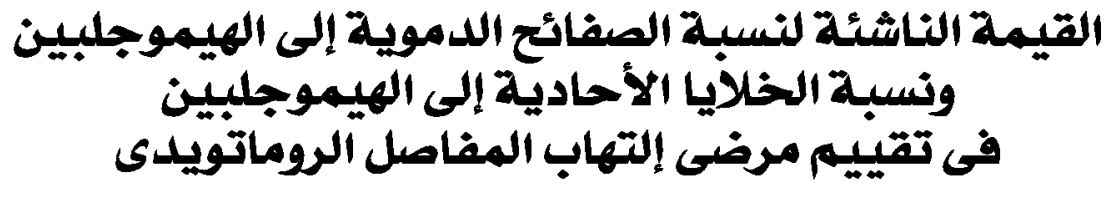

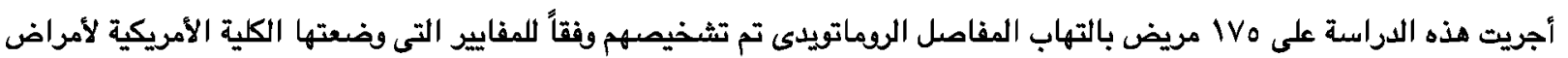

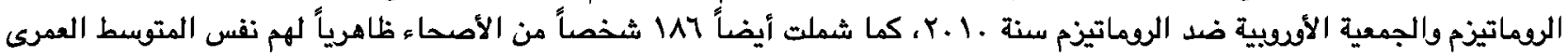

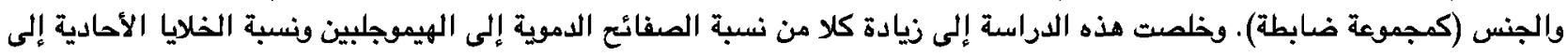

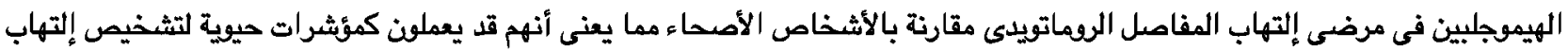

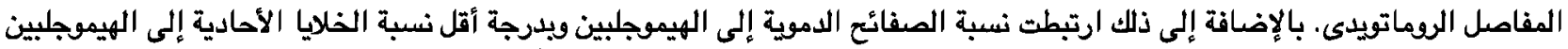

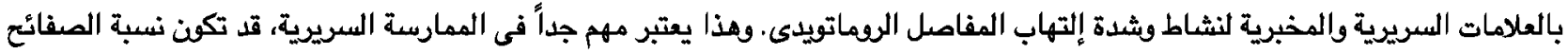

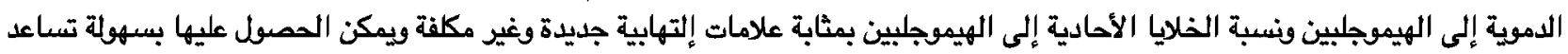
فى تقييم ورصد نشاط وشيدة إلتهاب المفاصل الرئه الروماتويدى. 